\title{
Intrauterine Ductus Arteriosus Constriction. Analysis of a Historic Cohort of 20 Cases
}

\author{
Stelamaris Luchese, João L. Mânica, Paulo Zielinsky \\ Porto Alegre, RS - Brazil
}

\begin{abstract}
Objective - To describe the relative incidence, presentation, and evolvement of fetuses with early ductus constriction.

Methods - Twenty fetal echocardiograms indicating ductus constriction were reviewed in a population of 7000 pregnants.
\end{abstract}

Results - The cases were divided into group A (related to maternal use of cyclooxygenase inhibitors [ $n=7]$ and group $B$ (idiopathics [ $n=13]$ ). Mean gestational age was 32.5 3.1 (27-38) weeks and maternal age was $28.2 \pm 8.5$ (17-42) years. Mean systolic velocity in the ductus was $2.22 \pm 0.34(1.66-2.81) \mathrm{m} / \mathrm{s}$, diastolic velocity $0.79 \pm 0.28(0.45-1.5) \mathrm{m} / \mathrm{s}$, and pulsatility index $1.33 \pm 0.36$ (0.52-1.83). Two cases of ductal occlusion were noted. In $65 \%$ of the cases, an increase occurred in the right cavities; in $90 \%$ of the cases, tricuspid or pulmonary regurgitation, or both, occurred, with functional pulmonary atresia in 1 case. Diastolic velocity was greater in group $A$ $(1.13 \pm 0.33)$ than in group $B(0.68 \pm 0.15)(P=0.008)$. The other data were similar in the 2 groups. The evolvement was not favorable in 4 patients from group B, including 1 death and 2 cases of persistent pulmonary hypertension.

Conclusion - The high incidence of idiopathic constriction of the ductus arteriosus suggests that its diagnosis is underestimated and that many cases of persistence of fetal circulation in newborns may be related to constriction of the ductus arteriosus not diagnosed during intrauterine life. Group B had a lower severity but a risk of an unfavorable evolvement, suggesting a distinct alteration.

Keywords: fetal cardiology, echocardiography, gestation

Instituto de Cardiologia do Rio Grande do Sul/Fundação Universitária de Cardiologia Mailing address: Stelamaris Luchese - Unidade de Pesquisa do IC/FUC

Av. Princesa Isabel, 395 - 90620-001 - Porto Alegre, RS - Brazil

E-mail: pesquisa@cardnet.tche.br

Received - 7/30/02

Accepted - 1/14/03
Premature constriction of the ductus arteriosus, in the absence of triggering factors, is considered a rare alteration, and experience with this defect is poor, both during pregnancy and in the neonatal period. Studies have demonstrated evidence of important repercussions, leading to heart failure and hydrops and may result in fetal or neonatal death in long-term cases ${ }^{1-3}$. The delay in diagnosis can lead to a persistent pulmonary hypertension in newborns, sometimes not responsive to available therapeutic interventions ${ }^{4,5}$. Fortunately, early diagnosis enables therapeutic intervention with improvement in the prognosis. If associated with the use of prostaglandin inhibitors and if the causal agent is removed in the beginning of the clinical picture, total recovery of the alterations may occur, without evidence of neonate complications ${ }^{6,7}$. However, constriction of the ductus arteriosus may be related to severe alterations when the diagnosis is delayed, fetal monitoring with echocardiography being of utmost importance ${ }^{8}$.

\section{Methods}

We reviewed the examinations and charts of the pregnant women undergoing fetal echocardiography at the Fetal Cardiology Unit(FCU) of the Instituto de Cardiologia do Rio Grande do Sul, from August 1997 to August 2001, in a population of 7000 pregnant women. To obtain the echocardiograms, we used ATL, (Advanced Technological Laboratories), model ULTRAMARK 9 Digital Plus Acuson model XP-10, and Acuson Aspen, with convex transducers 7 or $5 \mathrm{MHz}$ and/or a sectorial phased array of 3.5 or $5 \mathrm{MHz}$. All examinations were performed by ICU pediatric cardiologists with experience in fetal echocardiography. Constriction of the ductus was determined by the presence of turbulent flow in the ductus arteriosus, associated with systolic velocity greater than $1.4 \mathrm{~m} / \mathrm{s}$ and diastolic velocity greater than $0.3 \mathrm{~m} / \mathrm{s}$, in association with a pulsatility index smaller than $1.9^{9}$, which was calculated by the systolic velocity minus the diastolic velocity, divided by the mean velocity. In patients with total occlusion of the ductus arteriosus, the absence of ductal flow was analyzed.

Twenty fetuses fulfilled the diagnostic criteria and for- 
med the study group. The cases detected were followed up with fetal or neonatal echocardiography, and charts were reviewed. We did not include fetuses whose follow-up was not performed or those who had structural heart defects. The cases were divided into group A, with 7 fetuses in which the cause was secondary to maternal use of prostaglandin inhibitors, and group B, with 13 fetuses in which the cause was not determined and was therefore considered idiopathic. Gestational age was determined based on the last menstrual period. Maternal age and obstetric history including the number of pregnancies and labors were obtained from chart data. Hemodynamic involvement was considered mild in the presence of mild tricuspid regurgitation and/or mild pulmonary regurgitation; moderate in the presence of tricuspid or pulmonary regurgitation associated with right cavity enlargement; severe in the presence of severe tricuspid and/or pulmonary regurgitation, pulmonary functional atresia, cavity enlargement with right ventricular hypertrophy and/or contractile dysfunction, or total occlusion of the ductus arteriosus, fetal hydrops, and, alternatively, in the presence of a pulsatility index lower than 1 associated with any hemodynamic repercussions. To evaluate hemodynamic involvement between the groups, the severity score was formulated, considering 0 the absence of hemodynamic alterations, 1 the mild involvement, 2 the moderate involvement, and 3 the severe involvement. Evolvement was considered favorable when regression of the alterations occurred and in the absence of any associated complications.

In the statistical analysis, numerical data are presented as mean \pm standard deviation(SD), median and interquartile range (25th percentile [P25], 75th percentile [75]). For comparison of the variables, gestational age and maternal age, systolic velocity, diastolic velocity and pulsatility index, whose distributions were symmetric (normal) between the groups, the Student $t$ test was used. For the analysis of the severity score variable, the Mann-Whitney U test was used, and for the evolvement variable, Fisher's exact test was used, and odds ratio and $95 \%$ confidence interval (CI $95 \%$ ) were calculated. In the statistical analysis, we accepted $\mathrm{P}<0.05$ as statistically significant.

\section{Results}

The group studied comprised 20 fetuses with diagnoses of premature constriction of the ductus arteriosus, and we performed 47 fetal echocardiograms. The same examiner with expertise in fetal cardiology diagnosed $85 \%$ (17) of the cases. Gestational age ranged from 27 to 38 weeks, with a mean age of $33 \pm 2.9$ weeks and a median of 28 weeks. Maternal age ranged from 17 to 42 years, with a mean age of $27 \pm$ 8.4 years and a median of 28 years. Concerning obstetric history, the median number of pregnancies was 2 and the median number of labors was 1 . The maximum number of pregnancies reported was 7 for 6 labors.

Comparing groups $\mathrm{A}$ and $\mathrm{B}$, we did not observe significant differences regarding gestational age and maternal age $(\mathrm{P}=0.19$ and $\mathrm{P}=0.58$, respectively $)($ tab. $\mathrm{I})$.
The study of velocity flow from the patent ductus arteriosus demonstrated systolic velocity peak, ranging from 1.66 to $2.81 \mathrm{~m} / \mathrm{s}($ mean $=2.22 \pm 0.34 \mathrm{~m} / \mathrm{s})$, and diastolic velocity ranging from 0.45 to $1.5 \mathrm{~m}$ (mean $=0.79 \pm 0.28 \mathrm{~m} / \mathrm{s}$ ). Mean pulsatility index was $1.33 \pm 0.36$, ranging from 0.52 to 1.83 (fig. 1A, B). In table II, we describe the total and comparative values of systolic and diastolic velocities and pulsatility index between the patients whose cause was related to the use of cyclooxygenase-inhibiting drugs (group A) and the patients whose cause was not determined (group B). In 2 fetuses, we verified total occlusion of the ductus arteriosus (tab. II).

Regarding cause, only 7 of the 20 cases were related to the use of cyclooxygenase-inhibiting drugs (group A), corresponding to $35 \%$ of the cases. Associated drugs include indomethacin in 3 pregnant women, aspirin in 2 women, and sodium diclofenac in 2 women. In the other 13 fetuses (group B) no maternal history existed of drugs capable of interfering with the prostaglandin route. Table III demonstrates maternal and gestational age, the number of pregnancies and labors, the indication for examination and the medications used.

In table IV, we list all the patients from the sample, and we describe the echocardiographic data, including evaluation of the ductus flow in the Doppler examination, hemodynamic repercussions (cardiac cavity involvement, valvular alterations, signs of cardiac failure), and the evolvement of the patients. Regarding hemodynamic repercussions, apart from 2 fetuses $(10 \%)$, the other patients experienced tricuspid and/or pulmonary regurgitation, which varied from mild to severe, with functional pulmonary atresia in 1 fetus. Thirteen fetuses $(65 \%)$ had an increase in the right atrium or right ventricle, which was important in most cases. Hypertrophy, or right ventricle contractile dysfunction, or both, occurred in 7 cases (35\%). One of the fetuses had signs of decompensated heart failure with severe hydrops. In 2 fetuses, one in each group, with important hemodynamic repercussions, the septum primum was displaced to the left, with a decrease in its mobility, and in one of these fetuses we also observed pulsatile umbilical venous flow.

All the 7 cases with a history of the use of prostaglandin drug inhibitors evolved favorably after suspension of the medications. Five patients underwent control fetal echocardiographic examination, performed 4 days and 7 weeks after suspension of the medication, which demonstrated normalization of the altered findings. Two fetuses were followed-up after birth and both evolved without complications.

\begin{tabular}{|lrrrrr|}
\hline \multicolumn{7}{|c|}{ Table I - Gestational and maternal age } \\
\hline Age years & \multicolumn{2}{c}{ Group A (n=7) } & Group B (n=13) & P \\
& Mean (SD) & Median & Mean (SD) & Median & \\
\hline Gestational & $31.9 \pm 3.3$ & 33 & $32.9 \pm 3.1$ & 33 & 0.19 \\
Maternal & $29 \pm 8.9$ & 28 & $27.8 \pm 8.6$ & 28 & 0.58 \\
\hline Student $t$ test. & & & & \\
\hline
\end{tabular}




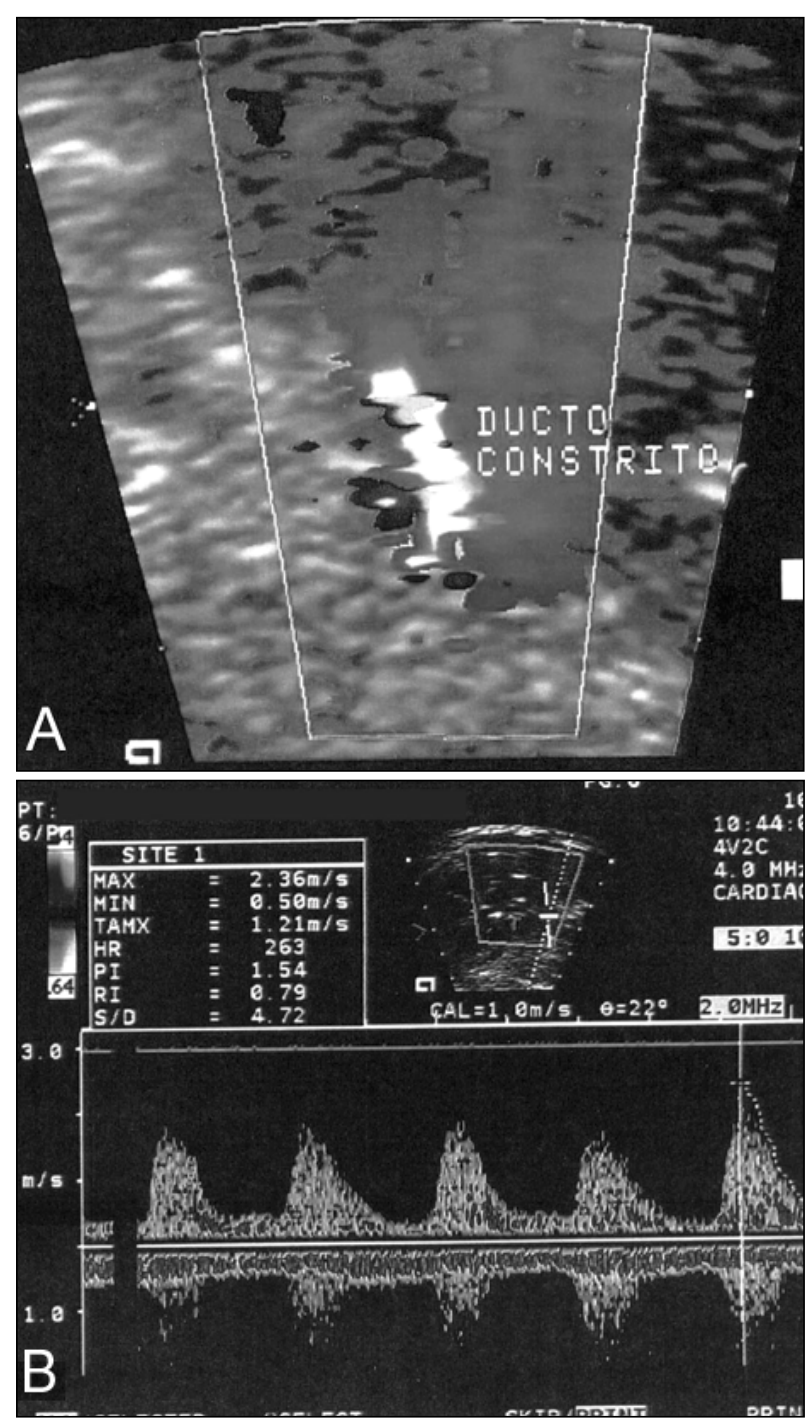

Fig. 1 - Color Doppler studies (A) and continuous (B) in the intrauterine ductus arteriosus constriction.

In the 13 cases where the cause was not determined, the evolvement was the following: in 9 cases $(69.2 \%)$, the echocardiogram demonstrated normalization of flows, 6 during fetal life and 3 during the neonatal period. One fetus in this group had ductus occlusion; the diagnosis was confirmed just after birth, the right cavity enlargement regressed, and the follow-up was satisfactory. In one case, where persistence of alterations in the fetal echocardiogram was observed, the evolvement was favorable after birth, no further abnormalities were detected, and the patient evolved without complications. Two patients, with worsening in the control fetal echocardiogram, had persistent pulmonary hypertension as newborns, requiring mechanical ventilation and prolonged hospitalization; afterwards, these alterations regressed and the patients evolved without apparent sequelae. One patient with clinical features of severe hydrops evolved in preterm delivery nonresponsive to inhibition of premature labor, and the newborn, extremely premature, died within the first hours of birth. In 4 patients with unfavorable results, 1 death occurred before the institution of adequate therapeutic measures. In another fetus, with worsening in contractile dysfunction in the control examination performed in the 37th week of pregnancy, interruption of pregnancy was recommended. In the other 2 fetuses, we opted for expecting conduct, monitoring with fetal echocardiography (tab. IV).

Table $\mathrm{V}$ demonstrates the evolvement of patients in both groups, classifying it as favorable or unfavorable. Table VI presents a severity score for each of the groups.

\section{Discussion}

Doppler echocardiography evaluation is sensitive for diagnosing intrauterine constriction of the ductus arteriosus. To avoid confusion in the diagnosis because of an increase in ventricular output, only fetuses with a pulsatility index lower than 1.9 were included in the study ${ }^{9}$. In one of the fetuses admitted with a diagnosis of aortic coarctation, the examination was repeated in the neonate period, this diagnosis then being eliminated.

Ductal constriction usually occurs after the use of cyclooxygenase-inhibiting drugs and is reversible after discontinuation of the medication, especially when diagnosed early ${ }^{10}$. With the increase in gestational age, the ductus becomes more sensitive to constricting factors ${ }^{8,11}$, demonstrating an increased incidence of ductus constriction after the 31 st gestational week ${ }^{12}$, being rare before the 27 th week. According to these data, we observed a mean gestational age of 33 weeks and a minimum of 27 weeks.

Ductal constriction is rare, when not related to the use of prostaglandin inhibitors ${ }^{13-15}$. The high number of idiopathic cases raises some questions, among them the possibility that this diagnosis is already underestimated. The performance of fetal echocardiography in a referral service, conducted by an experienced examiner, may have reduced the false-negative results. We observed a high number of cases coming from the private sector, which are usually mo-

\begin{tabular}{|c|c|c|c|c|}
\hline \multicolumn{5}{|c|}{ Table II - Flow in ductus arteriosus } \\
\hline & $\begin{array}{c}\text { Group A } \\
\text { Mean (SD) }\end{array}$ & $\begin{array}{l}\text { Group B } \\
\text { Mean (SD) }\end{array}$ & $\begin{array}{c}\text { Total } \\
\text { Mean (SD) }\end{array}$ & $\mathrm{P}$ \\
\hline Systolic velocity $(\mathrm{m} / \mathrm{s})$ & $2.28 \pm 0.39$ & $2.20 \pm 0.33$ & $2.22 \pm 0.34$ & 0.68 \\
\hline Diastolic velocity $(\mathrm{m} / \mathrm{s})$ & $1.13 \pm 0.33$ & $0.67 \pm 0.17$ & $0.78 \pm 0.29$ & 0.008 \\
\hline Pulsatility index & $1.12 \pm 0.43$ & $1.43 \pm 0.28$ & $1.34 \pm 0.36$ & 0.08 \\
\hline
\end{tabular}




\begin{tabular}{|c|c|c|c|c|c|c|}
\hline \multicolumn{7}{|c|}{ Table III- Clinical characteristics of cases } \\
\hline Group & $\mathrm{N}$ & $\begin{array}{c}\text { GA } \\
\text { (weeks) }\end{array}$ & $\begin{array}{l}\text { Mother } \\
\text { (years) }\end{array}$ & $\begin{array}{c}\text { Gestation/ } \\
\text { labor }\end{array}$ & Indication & Medications \\
\hline $\mathbf{A}$ & 1 & 33 & 42 & IV/III & Maternal heart disease & AAS, amiodarone, digital \\
\hline $\mathbf{A}$ & 2 & 35 & 39 & $\mathrm{II} / \mathrm{I}$ & DMG, polyhydramnios cardiomegaly & Sodium diclofenac \\
\hline A & 3 & 31 & 24 & $\mathrm{II} / \mathrm{I}$ & Hypertension, polyhydramnios & Indomethacin \\
\hline A & 4 & 27 & 28 & III/II & Suicide attempt & Indomethacin \\
\hline A & 5 & 34 & 30 & $\mathrm{VII} / \mathrm{VI}$ & GDM, polyhydramnios & Indomethacin \\
\hline A & 6 & 35 & 23 & $\mathrm{II} / \mathrm{I}$ & Fetal arrhythmia & Sodium diclofenac \\
\hline $\mathbf{A}$ & 7 & 28 & 17 & $\mathrm{I} / 0$ & Diabetes mellitus & AAS, Levonorgestrel + Ethynyl estradiol \\
\hline B & 8 & 33 & 19 & $\mathrm{I} / 0$ & Oligohydramnios/IURG & No \\
\hline B & 9 & 27 & 32 & $\mathrm{II} / \mathrm{I}$ & Gemellary/hydrocephali & No \\
\hline B & 10 & 37 & 17 & $\mathrm{I} / 0$ & Clinical appointment (day F) & No \\
\hline B & 11 & 36 & 35 & $\mathrm{II} / \mathrm{I}$ & Suspect of AOCO & No \\
\hline B & 12 & 34 & 21 & $\mathrm{I} / 0$ & Clinical appointment & No \\
\hline B & 13 & 31 & 32 & V/III & GDM & No \\
\hline B & 14 & 34 & 36 & $\mathrm{III} / \mathrm{I}$ & Clinical appointment & No \\
\hline B & 15 & 32 & 25 & $\mathrm{II} / 0$ & Clinical appointment & Bromhexine Chlorinate \\
\hline B & 16 & 28 & 41 & III/II & Severe hydrops & No \\
\hline B & 17 & 38 & 17 & $\mathrm{I} / 0$ & Right kidney hypoplasia & No \\
\hline B & 18 & 32 & 20 & $\mathrm{II} / \mathrm{I}$ & Single umbilical artery & Isometheptene \\
\hline B & 19 & 33 & 28 & $\mathrm{II} / \mathrm{I}$ & Fetal arrhythmia & No \\
\hline B & 20 & 33 & 39 & IV/I & Clinical appointment & Propolis \\
\hline
\end{tabular}

\begin{tabular}{|c|c|c|c|c|c|c|c|c|}
\hline \multicolumn{9}{|c|}{ Table IV - Doppler-echocardiography and evolvement data } \\
\hline \multirow[t]{2}{*}{ Group } & \multirow[t]{2}{*}{$\mathrm{N}$} & \multirow{2}{*}{$\begin{array}{c}\text { GA } \\
\text { (weeks) }\end{array}$} & \multicolumn{2}{|c|}{ Velocity $(\mathrm{m} / \mathrm{s})$} & \multirow[t]{2}{*}{ PI } & \multirow[t]{2}{*}{ Cavity alterations } & \multirow[t]{2}{*}{ Valvar alteration } & \multirow[t]{2}{*}{ Evolvement } \\
\hline & & & Sys & Dias & & & & \\
\hline A & 1 & 33 & 2 & & 1.37 & Normal & Moderate TR & Normal at birth \\
\hline \multirow[t]{2}{*}{ A } & 2 & 35 & 2 & 1 & 0.6 & RV/RA dilated & Severe TR & Normal at birth \\
\hline & & & & & & hypocontractile & Functional PA & \\
\hline A & 3 & 31 & 2.81 & 0.89 & 1.44 & Dilated RV & Mod/severe TR & 36 weeks normal \\
\hline A & 4 & 27 & & & 1.34 & Normal & Mild PR & 31 weeks normal \\
\hline A & 5 & 34 & \multicolumn{2}{|c|}{ Occluded ductus } & & Dilated/hypercontractile RV & & 35 weeks normal \\
\hline \multirow[t]{2}{*}{ A } & 6 & 35 & 2.6 & 1.5 & 0.52 & Dilated RV/RA & Severe TR/PR & Better at birth \\
\hline & & & & & & SP mobility decrease & & \\
\hline A & 7 & 28 & 2 & & 1.44 & Normal & Mild PR & 30 weeks normal \\
\hline \multirow[t]{2}{*}{ B } & 8 & 33 & 1.8 & & 1.51 & Dilated RV/RA & Mild PR & $\mathrm{PH}$ at birth \\
\hline & & & & & & Hypertrophic RV & & \\
\hline B & 9 & 35 & 2.19 & 0.72 & 0.88 & Dilated/hypocontractile RV & Moderate TR & $\begin{array}{l}\text { severe IT at } 37 \text { weeks } \\
\mathrm{PH} \text { at birth }\end{array}$ \\
\hline B & 10 & 37 & 2.43 & 0.69 & 1.38 & Dilated RV/RA/PT & Minimum TR & Normal at birth \\
\hline \multirow[t]{3}{*}{ B } & 11 & 36 & \multirow{3}{*}{\multicolumn{2}{|c|}{ Occluded ductus }} & & Dilated RV/RA/LV & Severe TR/PR & Good neonate evolvement \\
\hline & & & & & & hypertrophic RV & & \\
\hline & & & & & & $\begin{array}{l}\text { SP mobility } \\
\text { decrease }\end{array}$ & & \\
\hline B & 12 & 34 & 2 & & 1.77 & RV mild dilation & Minimum TR & Better at 35 weeks \\
\hline B & 13 & 31 & 1.87 & & 1.83 & Normal & Mild PR & 37 weeks normal \\
\hline B & 14 & 34 & 2.69 & 0.68 & 1.73 & RV/RA dilated & Mild PR & 37 weeks normal \\
\hline B & 15 & 32 & 2.12 & 0.64 & 1.38 & Dilated/hypercontractile RV & & 36 weeks normal \\
\hline \multirow[t]{2}{*}{ B } & 16 & 28 & 2.14 & 0.66 & 1.15 & Dilated RV & Moderate TR & Neonate death \\
\hline & & & & & & Severe hydrops & & \\
\hline B & 17 & 38 & 2.64 & 0.96 & 1.47 & Normal & No & Good neonate evolvement \\
\hline B & 18 & 32 & 2.5 & 0.8 & 1.1 & Normal & Moderate TR & 34 weeks normal \\
\hline \multirow[t]{2}{*}{ B } & 19 & 33 & 2.36 & 0.5 & 1.54 & Dilated RV/RA & Mild PR & Good neonate evolvement \\
\hline & & & & & & Hypertrophic RV & & \\
\hline B & 20 & 33 & 1.66 & 0.45 & 1.55 & Normal & No & 34 weeks normal \\
\hline
\end{tabular}




\begin{tabular}{|lcc|}
\hline \multicolumn{3}{|c|}{ Table V - Evolvement } \\
\hline Favorable & Unfavorable \\
\hline Group A & 7 & 0 \\
Group B & 9 & 4 \\
\hline Fisher's exact test $=0.25$; odds ratio $=$ 7.1 (IC 95\% 0.33 -153.77$).$ \\
\hline
\end{tabular}

\begin{tabular}{|c|c|c|}
\hline \multicolumn{3}{|c|}{ Table VI - Hemodynamic involvement } \\
\hline & \multicolumn{2}{|c|}{ Severity score } \\
\hline & Mean (SD) & Median (P25 - P75) \\
\hline Group A & $2.14 \pm 0.9$ & $2(1.0-3.0)$ \\
\hline Group B & $2.08 \pm 1.12$ & $2(1.8-3.0)$ \\
\hline
\end{tabular}

nitored with obstetric echocardiography, increasing the possibility of finding abnormalities. The fact that all pregnant women sent for clinical appointments were from group $\mathrm{B}$ (undetermined causes) reinforces the importance of fetal echocardiography.

A study evaluating the presence of antiinflammatory medication in the meconium ${ }^{16}$ demonstrated a positive association with pulmonary hypertension in newborns. There was a weak agreement with maternal history, probably because of free access to combined medications ${ }^{16}$. It is questionable whether a substance with antiinflammatory action used as tea or natural medication may be deleterious. For this investigation, a directed questionnaire may be required to meet the Bradford-Hill casualty criteria. The association with drugs that enhance the sensitivity of the ductus arteriosus, such as retinoic acid ${ }^{17,18}$, should be investigated. We reported the use of other medications in both groups, however, with unknown effects on prostaglandin inhibition. We did not observe the association of corticoid with indomethacin, that are synergic factors ${ }^{20}$.

Regarding echocardiographic data, diastolic velocity was significantly greater in the group with undetermined causes (group B). As $65 \%$ of the patients (13/20) had right ventricular dilation or contractile dysfunction, or both, the evaluation of systolic velocity may be hindered, just as the pulsatility index is, because its assessment requires systolic velocity. Diastolic velocity may be a more reliable index, suggesting that the group related to the use of drugs is more affected, thus having a more favorable prognosis. Most patients (90\%) had functional involvement, $75 \%(15 /$ 20 ) were moderate to severe. We did not observe differences in the severity between groups, and one case occurred in each group of total occlusion of the ductus arteriosus and decrease in the mobility of the septum primum .

According to data from the literature, sodium diclofenac and indomethacin are more powerful inhibitors of cyclooxygenase than aspirin is ${ }^{21}$. In this study, all cases related to the use of prostaglandin inhibitors (group A) evolved favorably. It is expected that cardiac function normali- zes within 24 hours, or a few days after medication is suspended ${ }^{10}$. We observed normalization in control examinations 4 days to 7 weeks after drug suspension.

In the 13 cases where the use of prostaglandin inhibitors was not identified (group B), 9 fetuses (69.3\%) improved in clinical condition, 4 fetuses $(30.7 \%)$ showed worsening on the fetal echocardiogram, 2 fetuses had persistence of fetal circulation after birth, and 1 fetus died. Responsible factors for unfavorable evolvement may be related to intrinsic alterations in the ductus arteriosus, interfering with the prostaglandin or nitric oxide route, or even enhancing sensitivity to extrinsic constrictor factors ${ }^{22-24}$. Another possibility is the potential delay in diagnosis and the impossibility of withdrawing the causal agent. With the available data, we may estimate a -7.1-times greater relative risk for an unfavorable evolvement in patients with undetermined causes (group B), although it has not reached statistical significance(CI95\% $>0.33-153.77)$.

After ductal mechanical occlusion ${ }^{25}$ or secondary to antiinflammatory medication ${ }^{26,27}$, the increase in muscular pulmonary artery and pulmonary hypertension was demonstrated ${ }^{3,12,28,29}$. The patients from this study that evolved with persistence of fetal circulation after birth needed prolonged neonatal intensive care unit hospitalization but had a good response to treatment and satisfactory evolvement. A prior intrauterine diagnosis may have contributed favorably. It is estimated that pulmonary hypertension in newborns is idiopathic in $23 \%$ of cases ${ }^{30}$. It may be suggested that these cases are related to undocumented ductal constriction in fetal life, because of the number of idiopathic cases observed in this study, $15 \%$ of which (2/13) had pulmonary hypertension. None of these cases was related to maternal diabetes, a condition that may be associated ${ }^{30}$.

Echocardiography is indicated in nonimmune fetal hydrops, aiming at discarding ductus arteriosus constriction $^{3,31,32}$. The fetus with cavity enlargement and severe hydrops evolved with premature labor and died. In this case, we cannot infer the duration of ductal occlusion because of the precocious death.

In previous studies ${ }^{33,34}$, we observed that the use of nonhormonal antiinflammatory medications during pregnancy was related to the increase in ductus arteriosus patency in newborns. None of our patients had this complication; however, examining this was not the purpose of this study.

Currently, measures aiming at relaxation of the ductus arteriosus, in fetal life, are not available. Prostaglandin use in human fetuses for this purpose was not described. Experimental studies ${ }^{35}$ demonstrate positive effects with the use of endothelin antagonists, decreasing the consequences of ductal constriction. The possible role of nitric oxide in dilating the fetal ductus arteriosus has already been suggested ${ }^{23}$. Further studies are necessary aimed at specific treatment of premature constriction of the ductus arteriosus.

In the group of 20 fetuses with ductus arteriosus constriction, we observed a relatively high number of cases without a determined cause. Comparison of clinical and echo- 
cardiographic data demonstrated lower severity in the group with idiopathic constriction than in the group with ductal constriction secondary to maternal use of nonsteroidal antiinflammatory medication, but with a risk of unfavo- rable evolvement. Available data suggest that idiopathic ductus constriction is a functional alteration that differs from that dependent on maternal use of cyclooxygenaseinhibiting drugs.

\section{References}

1. Hofstadler G, Tulzer G, Altmann R, Schmitt K, Danford D, Huhta JC. Spontaneous closure of the human fetal ductus arteriosus: a cause of fetal congestive heart failure. Am J Obstet Gynecol 1996;174:879-83.

2 Mielke G, Steil E, Breuer J, Goelz R. Circulatory changes following intrauterine closure of the ductus arteriosus in the human fetus and newborn. Prenat Diagn 1998;18:139-45.

3. Downing GJ, Thibeault DW. Pulmonary vasculature changes associated with idiopathic closure of the ductus arteriosus and hydrops fetalis. Pediatr Cardiol 1994; 15:71-5.

4. Zenker M, Klinge J, Krüger C, Singer H, ScharfJ. Severe pulmonary hypertension in a neonate caused by premature closure of the ductus arteriosus following maternal treatment with diclofenac: a case report. J Perinat Med 1998;26,231-4

5. Niebyl JR, Witter FR. Neonatal outcome after indomethacin treatment for preterm labor. Am J Obstet Gynecol 1986;155:747-9.

6. Moise KJ Jr. Effect of advancing gestational age on the frequency of fetal ducta constriction in association with maternal indomethacin use. Am J Obstet Gynecol 1993;168:1350-3.

7. Bivins HA, JrNewman RB, FyfeDA, Campbell BA, Stramm SL. Randomized trial of oral indomethacin and terbutaline sulfate for the long-term suppression of preterm labor. Am J Obstet Gynec 1993;169:1065-70.

8. Vermillion ST, Scardo JA, Lashus AG, Wiles HB. The effect of indomethacin tocolysis on fetal ductus arteriosus constriction with advancing gestational age. Am J Obstet Gynecol 1997;177:256-61.

9. Tulzer G, Gudmundsson S, Sharkey AM, Wood DC, Cohen AW, Huhta JC. Doppler echocardiography of fetal ductus arteriosus constriction versus increased right ventricular output. J Am Coll Cardiol 1991;18:532-6.

10. Moise KJ Jr, Huhta JC, SharifDS et al. Indomethacin in the treatment of premature labor. Effects on the fetal ductus arteriosus. N Engl J Med 1988;319:327-31.

11. Tynan M. The ductus arteriosus and its closure. N Engl J Med 1993;18: 1570-2

12. Turner GR, Levin DL. Prostaglandin synthesis inhibition in persistent pulmonary hypertension of the newborn. Clin Perinatol 1984;11:581-9.

13. Harlass FE, DuffP, Brady K, Read J. Hydrops fetalis and premature closure of the ductus arteriosus: a review. Obstet Gynecol Survey 1989;44:541-3.

14. Mielke G, Steil E, Gonser M. Prenatal diagnosis of idiopathic stenosis of the ductus arteriosus associated with fetal atrial flutter. Fetal Diagn Ther 1997;12:46-9.

15. Yaman C,Arzt W, Tulzer G, Tews G. Spontaneous constriction of the fetal ductus arteriosus. Z Geburtshilfe Neonatol 1999;203:44-6.

16. Alano MA, Ngougmna E, Ostrea Jr EM, Konduri GG. Analysis of nonsteroidal antiinflammatory drugs in meconium and its relation to persistent pulmonary hypertension of the newborn. Pediatrics 2001;107:519-23

17. MommaK,ToyonoM,Miyagawa-TomitaS.Acceleratedmaturation of fetal ductusarteriosus by maternally administered vitamin A in rats. Pediatr Res 1998;43:629-32.

18. Wu G-R, Jing S, Momma K, Nakanishi T. The effect of vitaminA on contraction of the ductus arteriosus in fetal rat. Pediatric Research 2001;49:747-54.

19. Brezinka CH, Gittenberger-de Groot AC, Wladimiroff JW. The fetal ductus arteriosus, a review. Zentralbl Gynakol 1993;115:423-32.
20. Levy R, Matitiau A, Ben Arie A, Milman D, Or Y, Hagay Z. Indomethacin and corticosteroids: an additive constrictive effect on the fetal ductus arteriosus. Am J Perinatol 1999;16:379-83

21. Momma K, Hagiwara H, Konishi T. Constriction of fetal ductus arteriosus by non-steroidal anti-inflamatory drugs: study of additional 34 drugs. Prostaglandins 1984;28:527-36.

22. Heymann MA, Rudolph AM. Control of the ductus arteriosus. Physiol Rev. $1975 ; 55: 62-78$

23. Momma K, Toyono M. The role of nitric oxide in dilating the fetal ductus arteriosus in rats. Pediatr Res 1999;46:311-5.

24. Coceani F, Liu YA, Seidlitz E, Kuwaki T,Ackerley C, Yanagisawa M. Deletion of the endothelin-A-receptor suppresses oxygen-induced constriction but not postnatal closure of the ductus arteriosus. J Cardiovasc Pharmacol 2000; 36(suppl1):S75-7.

25. Wild LM, Nickerson PA, Morin FC. Ligating the ductus arteriosus before birth remodels the pulmonary vasculature bed of the lamb. Pediatr Res 1989;25:251-7.

26. Levin D, Fixler DE, Morris FC, Tyson J. Morphologic analysis of the pulmonary vascular bed in infants exposed in utero to prostaglandin synthetase inhibitors. J Pediatr 1978;92:478-83

27. Murphy JD, Rabinovich M, Goldstein JD, Reid LM. The structural basis of persistent pulmonary hypertension of the newborn infant. J Pediatr 1981;98:962-7.

28. Levin DL, Hyman AI, Heymann MA, Rudolph AM. Fetal hypertension and the development of increased pulmonary vascular smooth muscle: A possible mechanism for persistent pulmonary hypertension of the newborn infant. J Pediatrics 1978;92:265-9.

29. Manchester D, Margolis HS, Sheldon RE. Possible association between maternal indomethacin therapy and primary pulmonary hypertension of the newborn. Am J Obstet Gynecol 1976;126:467-9.

30. Van Marter LJ, Leviton A, Allred EN et al. Persistent pulmonary hypertension of the newborn and smoking and aspirin and nonsteroidal antiinflammatory drug consumption during pregnancy. Pediatrics 1996;97:658-63.

31. Momma K, Nishihara S, Ota Y. Constriction of the fetal ductus arteriosus by glucocorticoid hormones. Pediatr Res 1981;15:19-21.

32. Räsänen J, Debbs RH, Wood DC, Weiner S, Weil SR, Huhta JC. Human fetal right ventricular ejection force under abnormal loading conditions during the second half of pregnancy. Ultrasound Obstet Gynecol 1997;10:325-32

33. Norton ME, Merrill J, Cooper BAB, Kuller JA, Clyman RI. Neonatal complications after the administration of indomethacin for preterm labor. N Engl J Med 1993;329:1602-7.

34. Hammerman C, Glaser J, Kaplan M, Schimmel MS, Ferber B, Eidelman AI. Indomethacin tocolysis increases postnatal patent ductus arteriosus severity. Pediatrics 1998; 102:56.

35. Takizawa T, Horikoshi E, Shen MH, et al. Effects of TAK-044, a nonselective endothelin receptor antagonist, on the spontaneous and indomethacin- or methylene blue-induced constriction of the ductus arteriosus rats. J Vet Med Sci 2000;62:505-9. 